\title{
Efek Multiplier Dana Desa di Masyarakat Tani Desa Perbatasan NKRI-RDTL Kabupaten Timor Tengah Utara
}

Boanerges Putra Sipayunga, dan Umbu Jokab

${ }^{a}$ Fakultas Pertanian, Universitas Timor, Kefamenanu, TTU-NTT, Indonesia.Email: boanerges@unimor.ac.id

${ }^{b}$ Fakultas Pertanian, Universitas Timor, Kefamenanu, TTU - NTT, Indonesia.Email :umbujoka@unimor.ac.id

\begin{tabular}{|c|c|}
\hline Article Info & Abstrak \\
\hline $\begin{array}{l}\text { Article history: } \\
\text { Received } 17 \text { Januari } 2021 \\
\text { Received in revised from } 25 \text { Januari } 2021 \\
\text { Accepted } 30 \text { Januari } 2021\end{array}$ & $\begin{array}{l}\text { Village funds provided by the Central Government to Village Governments are } \\
\text { aimed at equitable distribution of the Indonesian economy. The Village } \\
\text { Government is expected to be able to manage village funds to accelerate } \\
\text { Indonesia's development, especially in disadvantaged areas. This study aims to }\end{array}$ \\
\hline $\begin{array}{l}\text { DOI: } \\
\text { https:/ /doi.org/10.32938/ag.v6i1.1246 } \\
\text { Keywords: } \\
\text { Village Fund } \\
\text { Multiplier Effect } \\
\text { Border Area }\end{array}$ & $\begin{array}{l}\text { analyze the multiplier effect of village funds in the border villages of the Republic } \\
\text { of Indonesia- Democratic Republic of Timor Leste, North Central Timor Regency. } \\
\text { The research was conducted in the border village of the Republic of Indonesia- } \\
\text { Democratic Republic of Timor Leste in June-August } 2020 \text {. The method used in this } \\
\text { research is quantitative descriptive. The results of this study indicate that the } \\
\text { multiplier effect rate in the research village is below 1.5. This shows that the use } \\
\text { of village funds until } 2020 \text { has not been optimal because the economic activities } \\
\text { carried out in border communities in North Central Timor Regency are still } \\
\text { relatively low. }\end{array}$ \\
\hline
\end{tabular}

\section{Pendahuluan}

Undang-undang No. 32 Tahun 2004 tentang Pemerintah Daerah telah diatur mengenai pelaksanaan sistem desentralisasi di Negara Indonesia, dimana pemerintah pusat memberikan kewenangan yang lebih besar kepada daerah untuk melakukan serangkaian proses, mekanisme dan tahapan perencanaan yang dapat menjamin keselarasan pembangunan. Desentralisasi fiskal yang dilakukan oleh pemerintah pusat bertujuan untuk melakukan percepatan ekonomi. Pada banyak kasus di beberapa negara, pendapatan dan desentralisasi fiskal berhubungan positif (Bodman,2011). Bentuk dari desentralisasi di Negara Indonesia salah satunya adalah dana desa. Desa diberikan kewenangan untuk mengatur pembelanjaan tergantung kebutuhan masyarakat desa tersebut.

Daerah perbatasan merupakan daerah dengan wilayah binaan yang sangat luas dengan penyebaran penduduk yang berpola tidak merata. Daerah perbatasan biasanya masuk dalam kriteria desa miskin dengan pertumbuhan cenderung lebih lambat dibandingkan dengan desa di sekitarnya. Faktor penyebab lambatnya pertumbuhan desa daerah perbatasan diantaranya: (a) Belum digali secara mendalam dan menyeluruh mengenai potensi sosial-ekonomi masyarakat di daerah perbatasan, yang merupakan faktor pendukung ketahanan masyarakat di wilayah perbatasan tersebut; (b) Lemah dan lambat kemampuan pelayanan sosial-ekonomi masyarakat di wilayah perbatasan dibandingkan dengan jumlah penduduk yang harus dilayani; dan (c) Kurang terdistribusinya secara merata pelayanan sosial dan ekonomi di wilayah perbatasan dilihat atas dasar lokasi atau agihan keruangan (spatial distribution) (Listiyah Miniarti, 1996).

Berdasarkan data BPS tahun 2015 dari 74.093 jumlah desa di seluruh Indonesia, terdapat 27,23 persen berkategori desa tertinggal, 68,85 persen desa berkembang, dan hanya $3,91 \%$ desa maju (BPS,2016). Adanya ketimpangan pembangunan antara Indonesia Timur dan Indonesia Barat, khususnya Jawa menjadi permasalahan tersendiri. Kemiskinan di pedesaan selalu menjadi penyebab utama perpindahan penduduk dari desa ke kota. Ketimpangan juga dapat dilihat dari pendapatan per kapita Indonesia dan pendapatan per kapita Kabupaten Timor Tengah Utara. Pada tahun 2019, pendapatan per kapita Indonesia mempunyai nilai 55 juta rupiah per tahun, sedangakan di Kabupaten Timor Tengah Utara sekitar 22 juta rupiah per tahun (BPS,2020). Penelitian ini bertujuan untuk menganalisis efek pengganda dana desa di Perbatasan NKRI-RDTL di Kabupaten Timor Tengah Utara.

\section{Metode}

Penelitian ini dilaksanakan pada desa perbatasan NKRI-RDTL di Kabupaten Timor Tengah Utara. Kecamatan yang menjadi sampel dalam penelitian ini adalah kecamatan yang memiliki perbatasan langsung dengan Negara RDTL. Setiap kecamatan dalam penelitian diambil dua desa sebagai sampel dalam penelitian ini. Penelitian ini dilaksanakan bulan Juni-September 2020. Data yang digunakan pada penelitian ini menggunakan data primer dan data sekunder. Data primer didapat melalui wawancara dengan masyarakat di Desa Perbatasan Kabupaten Timor Tengah Utara. Data sekunder didapat dari Badan Pusat Statistik Kabupaten Timor Tengah Utara. Daerah penelitian meliputi 6 desa yaitu Saenam, Napan, Haumeni Ana, Faenake, Sunsea, dan 
Manusasi. Desa yang menjadi daerah penelitian memiliki perbatasan langsung dengan negara RDTL. Jumlah populasi dari desa perbatasan yang menjadi tempat penelitian 6542 jiwa dengan 1600 KK. Jumlah responden diambil berdasarkan Tabel Isaac dan Michael dengan sampling eror $5 \%$ maka diperoleh jumlah responden sebesar 289, dan untuk memperkecil kesalahan data maka responden ditambahkan sebesar 100. Responden dalam penelitian ini berjumlah $390 \mathrm{KK}$. Metode penelitian yang digunakan dalam penelitian ini menggunakan deskriptif kuantitatif. Data kuantitatif pada penelitian ini dihitung menggunakan rumus:

$$
k=\frac{1}{1-(M P C * P S Y)}
$$

Keterangan:

$\mathrm{K}=$ pengaruh ekonomi wilayah

MPC = proporsi pendapatan petani yang dibelanjakan di daerah tersebut

PSY = bagian dari pendapatan petani yang menghasilkan pendapatan (Tiebout dalam Tambunan,2001).

\section{Hasil dan Pembahasan}

3.1. Gambaran Umum Responden

a. Pendidikan

Sumber daya manusia merupakan salah satu faktor penting dalam mengembang suatu daerah. Pendidikan yang menjadi salah satu indikator apakah masyarakat satu daerah mampu menerima pengembangan dengan lebih mudah. Tabel 1. merupakan lama pendidikan yang ditempuh oleh responden masyarakat desa perbatasan.

Tabel 1. Lama Pendidikan Yang Ditempuh Responden Masyarakat Desa Perbatasan

\begin{tabular}{ccc}
\hline Lama Pendidikan (Tahun) & Jumlah Responden (Orang) & Persentase (\%) \\
\hline$\leq 6$ & 277 & 71,02 \\
$\geq 7$ & 113 & 28,98 \\
\hline Total & 390 & 100 \\
\hline
\end{tabular}

Sumber: Data Primer; Diolah 2020

Berdasarkan Tabel 1. Bahwa masyarakat perbatasan lebih dari 50\% hanya menempuh pendidikan sebatas sekolah dasar. Masyarakat desa perbatasan yang menempuh pendidikan setelah sekolah dasar tidak lebih dari 30\%. Masyarakat desa perbatasan mayoritas berpendidikan rendah.

b. Pengalaman Bekerja

Pengalaman merupakan salah satu gambaran dari kemampuan mengelola dan mengatur di bidang pertanian. Pengalaman bekerja dapat membuat perbedaan antara satu individu dengan individu yang lain. Pengalaman responden desa perbatasan NKRI-RDTL Kabupaten Timor Tengah Utara dapat dilihat pada Tabel 2.

Tabel 2. Pengalaman Bekerja Responden Desa Perbatasan

\begin{tabular}{ccc}
\hline Lama Bekerja (Tahun) & Jumlah Responden (Orang) & Persentase (\%) \\
\hline $0-10$ & 26 & 6,66 \\
$11-21$ & 126 & 32,3 \\
$22-32$ & 128 & 32,82 \\
$33-43$ & 79 & 20,25 \\
$44-54$ & 26 & 6,66 \\
$55-65$ & 5 & 1,28 \\
\hline Total & 390 & 100 \\
\hline
\end{tabular}

Sumber: Data Primer;Diolah 2020

Berdasarkan Tabel. 2 dapat diketahui bahwa masyarakat desa perbatasan mayoritas sudah berpengalaman di bidang pertanian. Bertani merupakan cara hidup yang paling banyak dilakukan di desa perbatasan NKRI-RDTL Kabupaten Timor Tengah Utara.

3.2 Multiplier effect Masyarakat Tani Perbatasan NKRI-RDTL Kabupaten Timor Tengah Utara

Kabupaten Timor Tengah Utara merupakan salah satu kabupaten di Provinsi Nusa Tenggara Timur yang memiliki daerah perbatasan dengan Timor Leste yang mayoritas masyarakatnya adalah petani. Pertanian yang dilakukan masyarakat desa perbatasan masih 
bersifat tradisional karena kemampuan masyarakat di desa perbatasan mengelola pertanian masih menggunakan alat pertanian sederhana. Daerah yang bercirikan lahan kering ini mengakibatkan petani di desa perbatasan hanya melakukan aktivitas pertanian sekali setahun. Selebihnya masyarakat tani di desa perbatasan bergantung terhadap peternakan yang dilaksanakan dengan sistem peternakan lepas liar di padang. Rendahnya produktivitas masyarakat tani desa perbatasan merupakan kendala dalam pengembangan daerah perbatasan. Nilai multiplier effect masyarakat tani desa perbatasan dapat dilihat pada Tabel. 3.

Tabel 3. Nilai Multiplier effect Dana Desa di Masyarakat Tani Desa Perbatasan NKRI-RDTL

\begin{tabular}{ccc}
\hline No & Nama Desa & Angka Multiplier effect \\
\hline 1 & Haumeni Ana & 1,12 \\
2 & Manusasi & 1,39 \\
3 & Napan & 1,03 \\
4 & Faenake & 1,03 \\
5 & Sunsea & 1,02 \\
6 & Saenam & 1,08 \\
\hline
\end{tabular}

Sumber: Data Primer; Diolah 2020

Berdasarkan Tabel 3 dapat dijelaskan bahwa nilai multiplier effect dana desa di masyarakat tani di wilayah perbatasan, secara keseluruhan nilainya di bawah angka 1,5. Hal ini menunjukkan cukup rendahnya aktivitas ekonomi selama dana desa diberikan yang dilakukan masyarakat tani di desa yang ada di perbatasan NKRI-RDTL. Hasil ini jauh rendah jika dibandingkan dengan Syahza (2011), angka multiplier effect yang disebabkan oleh pembangunan perkebunan kelapa sawit diperoleh sebesar 3,3. Produktivitas yang rendah dan tidak didukung oleh pendidikan yang baik pada masyarakat tani di daerah perbatasan mengakibatkan rendahnya tingkat kreatifitas dalam menunjang produktivitas masyarakat itu sendiri. Hal ini sesuai dengan Abatan et al., (2020), pendidikan bukan sebagai faktor kuat dalam mempengaruhi pemberdayaan dalam mengikuti program yang didanai oleh dana desa. Pemberdayaan yang menghasilkan keberdayaan yang berimplikasi terdapatnya peningkatan pendapatan masyarakat.

Berdasarkan tabel 3 juga dapat dijelaskan bahwa Desa Manusasi memiliki nilai multiplier effect yang paling tinggi jika dibandingkan dengan nilai pada desa yang lain. Desa Manusasi yang terletak di Kecamatan Miomaffo Barat yang dikenal sebagai sentra tanaman hortikultura di Kabupaten Timor Tengah Utara. Desa Manusasi seharusnya bisa menghasilkan nilai multiplier effect yang lebih tinggi lagi karena sebagai salah satu pusat hortikultura yang memiliki kemampuan untuk menanam sepanjang tahun dengan kondisi lahan dan iklim yang sesuai dengan kondisi pertumbuhan dan hasil produksi tanaman.

Mayoritas masyarakat tani desa perbatasan berpengalaman bekerja di bidang pertanian lebih dari 10 tahun. Pengalaman yang tinggi pada usaha tani dan pendidikan yang rendah cenderung mengakibatkan masyarakat desa perbatasan hanya mengulangi hal yang sama untuk usaha tani (berdasarkan kebiasaan yang sering dilakukan). Adanya pembangunan infrastruktur yang dibangun melalui dana desa dan pemerintah pusat tidak menarik masyarakat perbatasan untuk mendapatkan informasi mengenai pertanian berorientasi bisnis. Pengalaman yang tinggi membuat masyarakat desa perbatasan tidak mau untuk terus berkembang karena mereka sudah percaya terhadap yang mereka lakukan sudah benar dan tidak perlu dikoreksi atau dikembangkan lagi. Hal ini sesuai dengan Selan (2019), pengalaman tidak berpengaruh signifikan terhadap curahan jam kerja, sehingga pengalaman yang tinggi tidak mencerminkan adanya manajemen yang baik dalam mengelola usaha tani masyarakat desa di wilayah perbatasan Kabupaten Timor Tengah Utara.

\section{Simpulan}

Multiplier effect desa perbatasan Kabupaten Timor Tengah Utara di bawah angka 1,5. Hal ini menunjukkan masih rendahnya aktivitas ekonomi yang dilakukan oleh masyarakat di desa perbatasan NKRI-RDTL Kabupaten Timor Tengah Utara.

\section{$5 \quad$ Ucapan Terima Kasih}

Peneliti mengucapkan terima kasih kepada Lembaga Penelitian dan Pengabdian Kepada Masyarakat Universitas Timor yang telah membantu penyelesaian penelitian dengan memberikan bantuan dana melalui skema pendanaan Penelitian Dosen Pemula dengan nomor: 48/UN60/LLPM/PP/2020. 


\section{Pustaka}

Badan Pusat Statistik.2016. Indikator Kesejahteraan Rakyat 2016. Badan Pusat Statistik. Jakarta.

2020. Indikator Kesejahteraan Rakyat 2020. Badan Pusat Statistik. Jakarta.

.2020. Kabupaten Timor Tengah Utara Dalam Angka 2020. Badan Pusat Statistik. Kefamenanu.

Bodman, P. (2011). Fiscal decentralization and economic growth in the OECD. Applied Economics, 43(23), 3021-3035.

Abatan, Yanuarius, Boanerges Sipayung,Umbu Joka,Agustinus Nubatonis.2020.Dana Desa Dan Pemberdayaan Masyarakat Desa Pesisir Pantai Utara Kabupaten Timor Tengah Utara(Studi Kasus Desa Tuamese).Di dalam: Asrul et al.,editor. Sinergi Peluang dan Tantangan Pembangunan Pertanian Menyongsong Era Society 5.0. Prosiding Seminar Nasional ke 3 Politeknik Pertanian Kupang;2020 Des 7;Kupang. Hlm 68-76.

Listiyah Miniarti, 1996. Peranan Potensi Prasarana dan 81 Sarana Sosial dan Ekonomi dalam Pengembangan Wilayah Perbatasan di Kab. Gunung Kidul Provinsi D.I. Yogyakarta, Skripsi S1. Yogyakarta: Fak. Geografi UGM.

Selan, M. F., \& Hutapea, A. N. (2019). Analisis Faktor Sosial Ekonomi yang Mempengaruhi Curahan Jam Kerja Wanita Tani Padi Sawah Di Desa Haekto Kabupaten Timor Tengah Utara. AGRIMOR, 4(4), 58-59.

Syahza, A. (2011). Percepatan ekonomi pedesaan melalui pembangunan perkebunan kelapa sawit.publikasiilmiah.ums.ac.id

Tambunan, Tulus T,H.2001. Transformasi Ekonomi Di Indonesia Teori dan Penemuan Empiris.Jakarta:Salemba Empat. 